ISSN 1112-9867

http://www.jfas.info

\title{
RELATIONSHIP BETWEEN SLEEP AND MOOD STATES AMONG STUDENT-ATHLETE OF MAJLIS SUKAN NEGERI (MSN), PERAK
}

\author{
K. N. May ${ }^{*}$ and N. A. Razak \\ Faculty of Sport Science and Coaching, Sultan Idris University of Education, 35900 \\ TanjungMalim, Perak, Malaysia
}

Published online: 10 November 2017

\begin{abstract}
This study aims to examine the relationship between sleep and mood states on student-athlete. The respondent consists of 89 student-athletes from MajlisSukanNegeri, Perak. There were 53 male respondent $(59.3 \%)$ and 36 female respondent (40.4\%). These respondent were range from age 13 to 21 years old are chosen from the category of individual and team sports. The instruments used were Profile of Mood States (POMS). For sleep status, result was sort out by two categories, which is normal sleep and sleep deprivation. There were 34 respondent with sleep deprivation condition (38.2\%) and 55 respondent with normal sleep condition $(61.8 \%)$. According to the results,Pearson's correlation showed positive relationship between sleep status and athlete's mood states. In conclusion, student-athletes showed more negative mood (depress and tension) in sleep deprived condition.
\end{abstract}

Keywords: sleep; sleep deprivation; normal sleep; mood states.

Author Correspondence, e-mail: author@gmail.com

doi: http://dx.doi.org/10.4314/jfas.v9i6s.99 


\section{INTRODUCTION}

Sleep has been identified by elite athletes, coaches, and sports trainers as a critical component for training and competition [1]. Despite anecdotal evidence suggesting that athletes are concerned about the impact that inadequate sleep can have upon performance [2], there is a scarcity within the literature examining how this behaviour affects training and competition psychological states and performance.

According to National Sleep Foundation [3] sleep is an essential for human brain because it is important to body functioning and brain activity to occur. Sleep deprivation or skipping sleep are very harmful to oneself and can lead to dead. Individuals with sleep deprivation will look bad, feel moody, and also perform poorly. Sleep is very important to human well-being. It is as important as the air we breathe, the food we eat and the water we drink. It is also can help to manage stress among teens.

According to American College Health Association, survey found that most of the student-athletes have insufficient sleep for four nights per week. There is also research showed that performance can enhance by sleep. Since most of the student-athletes have the problem of sleep deprivation, they must good in balancing between training and academic. They should made sleep as important as their part of daily life and wisely manage their time. Besides training and academic, most of the student-athletes still have other personal activities to pursue [4]. For example, private lessons and conditioning program. They may spend more time on work out in order to have an ideal body shape and appearance in spite of maintain physical fitness. They are at the age of young adults and starting to attract opposite gender. In 24 hours, these young athletes need to divide the time for training, academic coursework and social activities will make them physical and mental tiring. Many student-athletes do not manage their time well and neglect sleep. As a result, their attitude, performance and mood are affected due to sleep deprived.

Student-athletes are more likely to feel sluggish during training or easily to feel annoy when performing or learning new skill that they are not familiar with if they have sleep deprived problem. Furthermore, reaction times of an individual will reduce and it can affect negatively on decision making during performance. Athlete can lose his defensive position and eventually effect the performance outcome with even a half-second pause on reaction time 
during real performance. Psychological component like stress, anxiety and depression can be extended with sleep deprived, and these will increasing fatigue on individuals. These factors will also lead to emotional unstable and low confidence in own abilities.

Athlete whom at the age of adolescent and still in growing process are normally in hardcore training to build up and maintain their skill and abilities. With this condition, they should have adequate and quality sleep on every day for complete recovery and regeneration. During sleep, human body will produce growth hormones which help in growth and repairing damage tissue. Although when we are sleeping we stop all movements but bodily essential functioning still working for immune and lymphatics system's effect. If athlete do not have sufficient sleep and cannot achieve optimum recovery before the next training, it is harmful to his body. Physiological breakdown may occur and causing body unable to perform at optimum level if the problem continue for a longer times.

Sleep is a need and it is very important to everyone. Experts suggest adolescent need to have seven to nine hours of sleep, this is considered as normal sleep but student-athletes might not be able to sleep for long. They need to commit for school, homework, practice, training, family and friends. It is difficult for them to find the equation between sleep and all those commitment. Mood will indirectly influence by sleep. Athlete with sleep deprivation problem easily have mood fluctuation and cannot give the best performance. There are several study on the effect of sleep on mood, however, there is not much research on sleep pattern and problems among student-athletes. In fact, they are at high risk on sleep difficulties due to training, competition and also balancing athletics with academic. The aim of this study is to examine the relationship between sleep (normal/ deprivation) and mood on athlete SUKMA MSN, Perak.

\section{METHODS}

\subsection{Participants}

There were 89 student-athlete (53 male and 36 female) with the age from 13-21 are volunteered to take part in this study. These participants with average of 18 years old $(\mathrm{SD}=$ 1.9) are chosen from the category of individual and team sports. They are selected from MajlisSukanNegeri, Perak, representing their states in major tournament, not injured and do 
not have mood disorder. They are consistent in high-performance training and optimally adjust with regular school education. They are also participants who take part in Sukan Malaysia (SUKMA) 2016.

\subsection{Instruments}

Profile of Mood States (POMS) is chosen in the present study to identify the current mood states of athletes. POMS is a standard validated psychological test formulated by McNair et al., (1971)[4] and was originally developed as a brief measure of mood states among adolescent and adult populations. This questionnaire contains 65 items or statements and divided into six constructs: Anger, Confusion, Depression, Fatigue, and Vigour that describe feelings people have. This test requires participants to indicate for each items or statement how they have been feeling in the past week including today. Participants are ask to select the appropriate statement according to 5-point likert scale in order to indicate their feeling. They need to responds to the all 65 items or statements on the questionnaire, no time limit. When answering the questionnaire, participants are instruct to read each statement carefully which best indicates how you feel right now, at this very moment, even if this is not how you usually feel. Data will be collect and to be analyse. Score of total mood disturbance will be calculate and analyse according to the six constructs of mood profile: anger, confusion, depression, fatigue, tension, and vigour. The reliability and validity of POMS is Cronbach Alpha 0.63 to 0.96 [4].

\subsection{Procedures}

A briefly explanation on aim of the study is given to athletes during their break of training session. Consent forms are given to all participants to fill up. Instructions and descriptions for the questionnaire are given after they filled up consent form. All the participants were told to answer POMS questionnaire honestly in order for the data collection to examine their mood at the moment. There is no time limit on answering on the questionnaires. Participants should not feel the pressure when answering the questions. Data will be collect and to be analyse.

\subsection{Data Analysis}

The collected data is analysed using Statistical Package for Social Sciences (SPSS) software version 23. Pearson Correlation is used in the present study to relate sleep with athlete's mood states. 


\section{RESULTS AND DISCUSSION}

For sleep status, result was sort out by two categories, which is normal sleep and sleep deprivation. Normal sleep is at the range of more than or equal to seven hours, whereas sleep deprivation is less than seven hours. There were 34 respondent with sleep deprivation condition (38.2\%) and 55 respondent with normal sleep condition $(61.8 \%)$. The mean and standard deviation of sleep status were $1.4 \pm 0.5$ hours.

Table I. Pearson's correlations between normal sleep and Mood States of Athletes MSN,

Perak

\begin{tabular}{llcccc}
\hline & $\mathbf{2}$ & $\mathbf{3}$ & $\mathbf{4}$ & $\mathbf{5}$ & $\mathbf{6}$ \\
\hline 1. Anger & $.65^{* *}$ & $.82^{* *}$ & $.67^{* *}$ & $.81^{* *}$ & $.28^{*}$ \\
2. Confusion & & $.81^{* *}$ & $.64^{* *}$ & $.74^{* *}$ & .12 \\
3. Depression & & & $.71^{* *}$ & $.77^{* *}$ & .10 \\
4. Fatigue & & & $.66^{* *}$ & $.25^{*}$ \\
5. Tension & & & & .19 \\
6. Vigour & & & & \\
\hline
\end{tabular}

** Significant at the 0.01 level

Table II. Pearson's correlations between deprivation sleep and Mood States of Athletes MSN, Perak

\begin{tabular}{llcccc}
\hline & $\mathbf{2}$ & $\mathbf{3}$ & $\mathbf{4}$ & $\mathbf{5}$ & $\mathbf{6}$ \\
\hline 1. Anger & $.69^{* *}$ & $.87^{* *}$ & $.73^{* *}$ & $.73^{* *}$ & $.35^{*}$ \\
2. Confusion & & $.83^{* *}$ & $.84^{* *}$ & $.82^{* *}$ & .21 \\
3. Depression & & & $.88^{* *}$ & $.89^{* *}$ & .09 \\
4. Fatigue & & & $.76^{* *}$ & .20 \\
5. Tension & & & & .11 \\
6. Vigour & & & & \\
\hline
\end{tabular}

** Significant at the 0.01 level 
Results of first objective is to assess the correlation on sleep and mood states on athletes MSN, Perak. Athletes with normal sleep was significantly positive correlated to athletes' mood states of anger, confusion, depression and tension. Anger highly correlate to depression, $r(55)=$ $0.82, p<0.01$; and tension $r(55)=0.81, p<0.01$. Confusion also highly correlate to depression, $r(55)=0.81, p<0.01$ (see table I). Athletes still have high anger with depression and tension, and also high confusion with depression although have normal sleep. A one-tailed test of significance indicated the there was also a significant positive relationship between sleep deprivation condition with mood states of depression and tension, $r(34)=0.89$, $p<0.01$ (see table II). The longer the period of sleep deprivation, the more depress and tension the mood states of athletes.

\section{CONCLUSION}

The present study was aimed to examine the relationship between sleep status and mood states of athletes from MSN, Perak. Researcher want to know whether normal sleep condition or sleep deprive condition have any relationship with athlete's mood states. Results from the present study showed that there was a significant positive relationship between sleep deprivation condition with mood states of depression and tension $r(34)=0.89, p<0.01$. Athletes were more depress and tension when they were in the condition of sleep deprived, but they still vigor in training session. Besides that, athletes with normal sleep also was significantly positive correlated to athletes' mood states of anger, confusion, depression and tension. Anger has high correlation to depression and tension, $r(55)=0.82, r(55)=0.81, p<$ 0.01 respectively. Similarly, confusion also high correlation to depression, $r(55)=0.81, p<$ 0.01. This finding indicated that those athletes in the normal sleep condition still high in the mood of anger with depression and tension, and also confusion with depression.

Sleep was very important to human being especially for student-athletes. Sleep provides our body to physically and psychologically recover from the day, as well as for the mind to store memories of tasks that were learned that day[6]. Our brain uses sleep time to learn tasks that have been practiced during the day[6] and it has been shown to facilitate delayed learning of a skill, even without further physical practice [7]. This delayed learning is only achieved when a period of good quality sleep is completed within 24-hours of training. Increasing sleep has 
also been shown to cause a measureable increase in performance[8]. Previous studies found that adolescent requires between 8.5-9.25 hours of nocturnal sleep[9]. However, present findings indicated that $38.2 \%$ of the respondent normally obtained 6.1 hours of sleep. These findings stress that, similar to adolescents' sleep trends in the general population [10],adolescent, high-level student-athletes do not meet the experts' recommendations for sleep duration of healthy adolescents of between 7 to 11 hours of sleep [11]. As a results, they were depress and tension with sleep deprived condition.

Insufficient sleep can increase depressive symptoms. Irregular sleep schedules were also associated with greater depressive symptoms[12]. In a study of female college students, sleep debt of 2 hours per night and/or a bedtime after 2 am was associated with greater depressive symptoms[13]. Prolonged sleep latency was associated with loss of pleasure, punishment feelings, and self-dislike[14]. Moreover, insufficient sleep may elicit cognitive functioning which may depress an athlete's readiness to perform for training or competition [15]. Disrupted sleep negatively affects mood generalises to athletic populations[16], and mood is associated with subsequent athletic performance, it can be seen that disrupted sleep could negatively affect sporting performance via changes is mood states[17].

From the demographic data, majority of the respondent had 7 days for in-season schedule training in a week. The respondent in the present study were represented their state to compete in SUKMA 2016. They need to spend more time in athletics-related activities like training as preparation for the competition. As results, they showed negative mood like anger, confusion and depression although with normal sleep condition.

\section{REFERENCES}

[1] Samuels, C. (2008). Sleep, recovery, and performance: The new frontier in high performance athletics. Neurologic Clinics, 26, 169-180.

[2] Leger, D., Metlaine, A., \&Choudat, D. (2005). Insomnia and sleep disruption: Relevance for athletics performance. Clinical Sports Medicine, 24, 269-285.

[3] National Sleep Foundation (2013). Retrieved from:

http://www.sleepfoundation.org/article/sleep-topics/teens-and-sleep 
[4] MacNair, D. M., Lorr, M., \&Droppelman, L. F. (1971). EDITS manual for the profile of mood states.Editorial and Industrial Testing Service, San Diego, Calif.

[5] Venter, R. E. (2012). Role of sleep in performance and recovery of athletes: A review article. South African Journal for Research in Sport, Physical Education, and Recreation, 34(1), 167-184.

[6] Walker, M. P., \&Stickgold, R. (2005). It's practice, with sleep, that makes perfect: Implications of sleep-dependent learning and plasticity for skill performance. Clinics in Sports Medicine, 24(2), 310-317.

[7] Mah, C. D., Mah, K. E., Kezirian, E. J., \& Dement, W. C. (2011). The effects of sleep extension on the athletic performance of collegiate basketball players.Sleep, 34(7), 943-950.

[8] Matricciani, L., Blunden, S., Rigney, G., Williams, M. T. and Olds, T. S. (2013).

Children'ssleep needs: is there sufficient evidence to recommend optimal sleep for children? Sleep, 36(4), 527-534. doi: 10.5665/sleep.2538

[9] Gradisar, M., Gardner, G. and Dohnt, H. (2011). Recent worldwide sleep patterns and problems during adolescence: a review and meta-analysis of age, region, and sleep.Sleep Medicine, 12(2), 110-118. doi: 10.1016/j.sleep.2010.11.008

[10] Hirshkowitz, M., Whiton, K., Albert, S. M., Alessi, C., Bruni, O., DonCarlos, L. and Adams Hillard, P. J. (2015). National Sleep Foundation's sleep time duration recommendations: methodology and results summary. Sleep Health: Journal of the National Sleep Foundation. doi: 10.1016/j.sleh.2014.12.010

[11] Hershner, S. D., \&Chervin, R. D. (2014). Causes and consequences of sleepiness among college students.Nat Sci Sleep, 6, 73-84.

[12] Regestein Q, Natarajan V, Pavlova M, Kawasaki S, Gleason R, Koff E. (2010). Sleep debt and depression in female college students. Psychiatry Res; 176 (1):34-39.

[13] Brooks, P. R., Girgenti, A. A., \& Mills, M. J. (2009). Sleep patterns and symptoms of depression in college students. College Student Journal, 43(2), 464.

[14] Martinez, V. and Coyle, E. (2007). Sleep, pre-game fatigue, and game performance in female college soccer players.Journal of Sports Science and Medicine, Supplement 10 (P-107). 
[15] Mind to Muscle (2012). Retrieved

fromhttp://slco.org/recreation/hockeyYouth/pdf/Sleep_and_youth_athe.pdf

[16] Lastella, M., Roach, G. D., Halson, S. L. and Sargent, C. (2014). Sleep/wake behaviours of elite athletes from individual and team sports. European Journal of Sport Science, 1-7. doi: $10.1080 / 17461391.2014 .932016$

[17] Beedie, C. J., Terry, P. C., \& Lane, A. M. (2000). The profile of mood states and athletic performance: Two meta-analyses. Journal of applied sport psychology, 12(1), 49- 68.

\section{How to cite this article:}

May K. N. and Abdul Razak N. Relationship between sleep and mood states among student-athlete of Majlis Sukan Negeri (MSN), Perak. J. Fundam. Appl. Sci., 2017, 9(6S), 1346-1354. 